\title{
Erkek infertilitesi ve kanser arasındaki genetik örtüșme
}

\author{
Genetic overlap between male infertility and cancer
}

Sezgin Güneș ${ }^{1,2}$, Neslihan Hekim¹®, Sercan Ergün',2®

\section{öz}

Erkek infertilitesi heterojen ve multifaktöriyel etiyolojili bir bozukluktur. Son yıllarda yapılan bazı çalışmalar erkek infertilitesinin yalnızca sperm üretimindeki bir bozukluktan kaynaklanmadığı, bazı olgularda diyabet, kardiyovasküler hastalıklar ve kanser gibi sistemik bir bozukluğun bir parçası olabileceğini göstermektedir. Spermatogenez sürecindeki çok sayıdaki mitoz ve mayoz bölünmeler ve bazı çevresel faktörler, mutasyon/mutasyonlara neden olabilir ve kansere yol açabilir. Bu nedenlerle, erkek infertilitesi aslında kanser için bir erken belirteç olabilir. Bu derlemede erkek infertiltesi ve kanser arasındaki ortak genomik bulgular değerlendirildi.

Anahtar Kelimeler: Erkek infertilitesi, kanser, Y-kromozomu

\section{Gíriș}

Erkek infertilitesi heterojen ve multifaktöriyel etiyolojili bir bozukluktur. ${ }^{[1,2]}$ Erkek fertilitesi, genetik ve epigenetik faktörler, konjenital ya da kazanılmış ürogenital anomaliler, kanser, ürogenital enfeksiyonlar, skrotal ısının artışı, endokrin rahatsızlıklar, immunolojik faktörler ve toksik etkenlerin (sigara, ilaçlar, uyuşturucu, alkol vb.) etkisiyle azalabilmektedir. ${ }^{[1,3]}$ Dünya genelinde yaklaşık 186 milyon insanı etkilemektedir. ${ }^{[4]}$

Son yıllarda yapılan bazı çalışmalar erkek infertilitesinin yalnızca sperm üretimindeki bir bozukluktan kaynaklanmadığı$\mathrm{n}$, bazı olgularda diyabet ve kardiyovasküler hastalıklar gibi

${ }^{1}$ Ondokuz Mayıs Üniversitesi, Tıp Fakültesi, Tıbbi Biyoloji Anabilim Dalı, İzmir, Türkiye ${ }^{2}$ Ondokuz Mayıs Üniversitesi, Lisansüstü Eğitim Enstitüsü, Moleküler Tıp Anbilim Dalı, Izmir, Türkiye

\section{Yazışma Adresi/ Correspondence:}

Prof. Dr. Sezgin Güneş

Ondokuz Mayıs Üniversitesi Tıp Fakültesi, Tıbbi Biyoloji Anabilim Dalı, 55139

Samsun, Türkiye

Tel: $\quad$ +90362312 19 19/3164

E-mail: sgunes@omu.edu.tr

Geliş/Received: $\quad 26.02 .2021$

Kabul/ Accepted: 06.04 .2021

\section{ABSTRACT}

Male infertility is a highly heterogeneous disorder with multifactorial aetiology. Recent data have demonstrated that male infertility is not only an aberration in sperm production; however, infertility might be a part of various systemic diseases including diabetes, cardiovascular and cancer in some cases of infertility. High number of cell division by mitosis and meiosis during spermatogenesis and various environmental factors may lead to mutation/mutations result in cancer. Therefore, infertility might be an early marker for male infertility. This study reviews common genomic data regarding cancer and male infertility.

Keywords: Male infertility, cancer, Y-chromosome

sistemik bir bozukluğun bir parçası olabileceğini göstermektedir. ${ }^{[5]}$ Ayrıca, bazı epidemiyolojik çalışmalar, infertil erkeklerde kansere yatkınlığın olduğu öngörüldüyse de bununla ilgili genetik taramalar yapılmamıştır. Avrupa ve Amerika'da yapılan son çalışmalar fertilite bozukluklarının kanser ve diğer kronik hastalıklar ve mortalite ile ilişkili olabileceğini göstermiştir. Erkek infertilitesi ve kanser arasındaki ilişkinin en iyi incelendiği iki kanser çeşidi testis ve prostat kanseridir. ${ }^{[6]}$ İnfertilite testis ve prostat kanserinde olduğu gibi bazı hastalıklar için bir ön gösterge olabilir. Semen parametrelerinde bozukluk gözlenen erkeklerde, testis kanseri sıklı̆̆ının 20 kat daha fazla olabileceği, birinci derece akrabalarında ise riskin \%52 daha yüksek olduğu bildirilmiştir. ${ }^{[-10]}$ Benzer şekilde, Amerika’da 1967-1998 yılları arasında 22562 infertil erkeğin dâhil edildiği çalışma, infertilite tanısından sonra bu erkeklerin 168 'inde prostat kanseri geliştiğini göstermiştir. $\mathrm{Bu}$ infertil erkeklerde ileri evre prostat kanseri gelişme riski 2,6 kat yüksek bulunmuştur. ${ }^{[9]}$

$\mathrm{Bu}$ derlemenin amacı temel bilimci gözüyle son yıllarda erkek infertilitesi ve kanser arasındaki ilişki konusunda bir farkındalık oluşturmaktır. Ayrıca, semen parametrelerindeki bozuklukların kanserle olan ilişkisinin araştırılması amaçlanmıştır. 
Tablo 1. Kalıtsal kanserler ve infertilite ilişkilendirilen genler

\begin{tabular}{lccc}
\hline Gen & Infertilite Fenotipi & Herediter kanserlere yatkınlık sendromları & Reference \\
\hline ATM & Gonadal atrofi & Ataksi Telenjektazi & {$[24,25]$} \\
BRCA1 & NOA & Ailesel meme kanseri ve over kanseri & {$[26]$} \\
BRCA2 & Spermatogenic arrest & Ailesel meme kanseri ve over kanseri & {$[27]$} \\
$K I T$ & NOA, oligospermi & Ailesel gastrointestinal stromal tümör & {$[28]$} \\
MLH1 & Oligospermi & Muir torre sendromu, Lynch sendromu & {$[29]$} \\
VHL & NOA, oligospermi & VHL sendromu & {$[13]$} \\
WT1 & Infertilite & Wilms tümörü & {$[30,31]$} \\
\hline
\end{tabular}

NOA, nonobstrüktif azospermi.

\section{KANSER VE ERKEK INFERTILITESI}

Vücut hücreleri yaşamları süresince büyür, bölünür, hasar görür, yaşlanır ve ölür. Bu nedenle, organizmanın ihtiyaçlarını karşılamak amacıyla somatik hücreler mitozla bölünür ve çoğalırlar, gerektiğinde de ihtiyaç duyulan veya ölen hücrelerin yerini alır. $\mathrm{Bu}$ süreç, organizmanın yaşamı boyunca oldukça düzenli ve kontrollü olarak sürdürülmektedir. Ancak, bazen bu kontrollü süreçte küçük ya da büyük hatalar meydana gelebilir. Bu hatalar hücre bölünmesi sırasında kendiliğinden oluşabileceği gibi çevresel faktörlerin DNA'ya verebileceği hasar sonrasında da oluşabilir. Bu hatalar onarılmadığı zaman, hücreler kontrolsüz bir şekilde bölünmeye ve çevredeki dokulara yayılmaya başlar ve kanser meydana gelir. Bu hücreler, hataları çoğaldıkça programlı bir şekilde ölmek yerine bölünmeye davam eder ve anormal hücrelerin miktarı artar. ${ }^{[1]]}$ İnsanda kanserle ilişkilendirilen 202 gen bulunmaktadır. Kanserle ilişkilendirilen bu genlerden 116'sı normal bir hücrenin kansere dönüşümüne sebep olan genlerdir. Bu genlerden \%48’i hücrenin sağkalımı, \%44’ü hücrenin kaderinin belirlenmesi ve \%7'si genomun bütünlüğünün korunmasıyla ilişkilidir. ${ }^{[12]}$ Benzer bir sınıflandırmanın erkek infertilitesiyle de kurulabileceği öngörülmektedir. ${ }^{[13]}$ Nitekim erkek germ hücreleri, sürekli mitoz bölünmeler ve mayoz geçirmekte ve bu süreç ömür boyu devam etmektedir. ${ }^{[14]}$ Spermatogenez süreci, insanın diğer hücre hatlarıyla karşılaştırıldığında benzeri görülmeyen, hızlı ve organize bir süreçtir. ${ }^{[15]}$ Adölesan dönemi sonrasında gametlerde başlayan bu sürekli bölünmeler yaşla birlikte mutasyonların artmasına neden olmaktadır. ${ }^{[13,16]}$ Germ hücreleri bölünmeden önce sperm genomu iki katına çıkarılmaktadır. ${ }^{[15]}$ Genomun iki katına çıkarılma işleminden sorumlu olan enzim, DNA polimeraz, hem somatik hem de germ hücrelerinde her hücre bölünmesinde $1 / 10^{9}$ nükleotitde bir hata yapmaktadır. Bir diğer değişle her hücre bölünmesinde bir hata yapmaktadır. [17] Spermatogenezde ve somatik hücre bölünmesi sırasında mitoz bölünme öncesinde gelişen bu hatalar DNA onarım sistemleri ile engellenmektedir. ${ }^{[15]}$
Yeni tarihli bir meta-analiz fertilite bozukluğu olan erkeklerde testis ve prostat kanseri görülme olasılığının fertil erkelerle karşılaştırıldığında daha yüksek olduğunu göstermektedir. ${ }^{[6]}$ Testis kanseri, genç erkekler arasında görülür ve tüm kanserler arasında \%1,0-1,5 sıklıktadır. ${ }^{[18]}$ Yirmi binden fazla subfertil erkeğin dâhil edildiği geniş kohortlu bir çalışma düşük semen parametrelerine sahip erkelerde testis kanseri riskinin fertil erkeklerle karşılaştırıldığında \%50 arttığını göstermektedir. Ayrıca, motilite, morfoloji ve viabilite gibi sperm parametreleri ile testis kanseri arasında da bir ilişki bulunmuştur. Ancak, azospermi ve testis kanseri arasında ilişki bulunmamıştır. ${ }^{[10]}$ Diğer yandan, testis kanseri, hipogonadizm ve infertilite arasında da önemli bir ilişki bulunmaktadır. ${ }^{[19]}$ Nitekim mayotik arrest gözlenen hastalardan alınan testis dokusu örnekleri mutasyon sıklığının obstrüktif azospermik infertil hastaların kan örneklerindeki mutasyon sıklığından daha yüksek olduğu bulunmuştur. ${ }^{[20]}$

Prostat kanseri, erkeklerde en sık görülen kanser olup etiyolojisi çok iyi bilinmemektedir. Bilinen risk faktörleri yaş, aile öyküsü ve etnik kökendir. ${ }^{[21,22]}$ Son çalışmalar, bu risk faktörleri arasında baba olup olmamanın prostat kanseri ile ilişkili olabileceğini gösteren çalışmalar bulunmakla birlikte, sonuçlar genel olarak çelişkilidir. ${ }^{[23]}$ Nitekim, altı retrospektif çalışmanın dahil edildiği yakın tarihli bir meta-analiz erkek inferitilitesiyle prostat kanseri ve testis kanseri arasında istatistiksel olarak anlamlı bir ilişki ortaya koyamamıştır. ${ }^{[6]}$

Diğer yandan, kalıtsal kanserler germ hücre hattı mutasyonları ile kalıtılmaktadır. Hücre sağkalımı ve hücre bütünlüğünün korunmasından sorumlu genlerdeki mutasyonlar, hem infertilte hem de kanser için kalıtsal risk faktörleri olabilir. DNA onarımından, sorumlu genler, kanserde olduğu gibi erkek germ hücre hatlarının erken evrelerinde germ hücrelerinin genomik bütünlüğünün korunmasından sorumludur. ${ }^{[15]}$ Kalıtsal kanserlerden sorumlu olan ve infertilite ile ilişkilendirilen genler Tablo 1'de özetlenmiştir. 


\section{FARE MODELI VE INSAN}

\section{CCALIȘMALARINDA KANSER VE INFERTILITENIN ORTAK YÖNLERI}

Fare modelinde yapılan çalışmalarda, fare genomunda yaklaşık 1194 genin kanser, 666 genin ise infertilite ile ilişkili olduğu gösterilmiştir. Bu iki gen grubunun kesişimindeki 64 lokusun ortak olduğu ve bu genlerden \%10'unun erkek infertiltesiyle ilgili genleri kapsadığı görülmüşstür. ${ }^{[13]}$ Benzer bir yaklaşımla, insan kanser genleri ve fare ortolog (atasal kökeni aynı olan ancak farklı organizmalarla yapısal ve işlevsel benzerliği olan) infertilite genleri ile karşılaştırıldığında ise 25 genin erkek infertilitesi ve kanserle ortak olduğunu göstermiştir. Bu genlerden 19'unun normal hücreyi kansere sürükleyen genler, driver geneler, [\%44 tümör baskılayıc1 (ATM, BRCA1, BRCA2, CDKN2A, MLH1, PTCH1, RB1, SMAD4, STK11,VHL, WT1) \%32 onkogen (AR, CTNNB1, DNMT3A, FGFR3, H3F3A, KIT, $R E T$, TSHR) \%24 diğer] olduğu bulunmuştur. Kanser ve infertilitede ortak olan 25 genin fonksiyonları değerlendirildiğinde \%36'sının hücre sağkalımı, \%24'ünü hücre kaderi, 16'sının ise genomun bütünlüğünden sorumlu olduğu ortaya konulmuştur. ${ }^{[13]}$

\section{Y-KROMOZOMU, Y-KROMOZOMU MIKRODELESYONLARI VE KANSER}

Y-kromozomunun gonadal kanserlerden sorumlu olabileceği bilinmektedir. Nitekim, gonadal disgenezde, Y-kromozomunun düşük mozaisizm gösteren tam ya da fragmanlarının bulunması bile gonadoblastoma ile ilişkilendirilmiştir. Yaşa bağımlı olmayan Y-kromozomu kayıpları sigara kullanımına bağlı karsinogenezle ilişkilendirilmiştir. UTX delesyonu X kromozomunun homoloji gösteren bölümünde mutasyon olup olmamasına bağlı olarak solid tümörlerin $\% 80$ 'inde ve erkek lösemik hücre katlarında gözlenmiştir. ${ }^{[32]}$

Y-kromozomu mikrodelesyonları, azospermik ve ağır oligospermik erkeklerde en sık görülen genetik nedenlerden biriyse de hala moleküler seviyedeki etkilerinin bilinmeyenleri mevcuttur. Y-kromozomunun, spermatogenezden sorumlu genlerinde yer alan amplikonik diziler sürekli devam eden mitoz sürecinde delesyonlara, genomik kararsızlı̆ga ve infertiliteye neden olmakta ve testiküler germ hücreli tümör (TGCT) gelişimi riskinin artmasına yol açabilmektedir. ${ }^{[33]}$

Y-kromozomunda bulunan genlerin cinsiyetin belirlenmesi ve spermatogenezde rol oynadığı iyi bilinirken, bu genlerin diğer rolleri yeteri kadar bilinmemektedir. Yakın zamanda yapılan bazı çalışmalar Y-kromozomunun, bağışıklık ve bağışıklık yanıtı, graft versus host hastalığı, bazı kanser çeşitleri, kardiyak bozukluğunda, cinsiyet farklılıkları, nörolojik ve psikiyatrik hastalıklarda beynin cinsiyete özgü bozukluklarıyla ilişkilendirilmiştir. ${ }^{[34,35]}$

Y-kromozomu diğer kromozomlar gibi sentromerle ayrılmış kısa ve uzun iki koldan oluşmaktadır. Ancak, erkek mayozunda diğer kromozomlardan farklı olarak Y-kromozomunun homoloğu X-kromozomudur ve bu iki kromozom sadece terminal bölgelerinde rekombinasyon geçirir. ${ }^{[36]}$ Dolayısıla, Y-kromozomunun büyük bir bölümü rekombinasyona uğramamakta, rekombinasyona uğramayan bu bölge Y'nin erkek spesifik bölgesi (male-specific region of the Y chromosom; MSY) olarak adlandırılmaktadır. Ayrıca, MSY'de yer alan ve ilk kez azospermik erkeklerde tanımlan AZF (azospermia factor; AZF) bölgesi de burada yer almaktadır. ${ }^{[37]}$ AZF bölgesi, birbirleriyle kesişmeyen üç, $A Z F a, A Z F b$ ve $A Z F c$, bölgeye ayrılmaktadır ve bu bölgeler sırasıyla Y-kromozomunun uzun kolunun proksimal, orta ve distaline karşılık gelmektedir. Ayrıca, birbiriyle kesişen bir AZFbc bölgesi de bulunmaktadır. ${ }^{[3]}$ Bu bölgede bugüne kadar tanımlanan yaklaşık 200 dizilim etiketli bölge (sequence tagged site, STS) bulunmaktadır. STS'ler genomda sadece bir kez görülen 200-500 baz çifti uzunluğunda kısa DNA dizilimleridir. ${ }^{[38]}$ AZF bölgesinde, 28 'i protein ve 28'i kodlamayan RNA ve 188 'i psödogen olmak üzere toplam 244 gen bulunmaktadır. AZF genlerinin spermatogenezin korunması ve devamındaki rollerinin iyi bilinmesi ve bu delesyonu taşıyan kişilerin genel olarak sağlıklı görünmeleri nedeniyle başka fonksiyonlarının olabileceği üzerinde durulmamıştır. AZF bölgesinde protein kodlayan genlerin azlığı ve bu bölgedeki genlerin başka dokularda da eksprese edilmesi, Y-kromozomu mikrodelesyonu görülen erkeklerin başka hastalıklara da yatkınlığı olabileceğini göstermektedir. Y-kromozomunda protein kodlayan genlerin, birden fazla dokuda ifade edilmesi bunu destekleyen bir kanıt olmaktadır. Y-kromozomunda protein kodlayan genler birden fazla dokuda ifade edilenler ve sadece testiste ifade edilenler olmak üzere ikiye ayrilır. ${ }^{[39]}$ Nitekim, Y-kromozomunda lokalize olan, KDM5D geni prostat kanserinde tümör baskılayıcı ve bu genin kaybı prostat kanserinde agresivite ve metastazla ilişkilendirilmiştir. KDM5D promotöre bağlanmakta ve hücre döngüsünü kontrol ettiği düşülmektedir, çünkü kaybının hücre döngüsü ve mitoza hızlı giriş olduğunu göstermektedir. Ayrıca, KDM5D kaybı stres bağımlı DNA hasarıyla ilişkilendirilmiştir. Bir başka çalışma, KDM5Dìn androlojen reseptörü sinyal iletiminde rol oynadığı ve prostat kanseri tedavisinde docetaxel tedavisindeki duyarlılıkta rol oynadığı gösterilmiştir. ${ }^{[0]}$ Avrupalı geniş bir kohortu kapsayan yeni tarihli bir çalışma, AZFc $\mathrm{gr} / \mathrm{gr}$ subdelesyonlarının testiküler germ hücreli tümör 
gelişim riskinin yüksek olduğunu göstermiştir. ${ }^{[4]} U S P 9 Y$ ve RPS4Y2 genlerinin ifadesi prostat kanserinde, HSFY2 ifadesi, glioma, mide ve prostat kanserinde arttı̆̆ bulunmuştur. DDX3Y, UTY, KDM5D ve ELF1AY genlerinin ise farklı kanserlerde ifadesinin arttığı bulunmuştur. Tiroit, akciğer, karaciğer, pankreas, baş ve boyun, kolorektal, urotelyal renal, prostat, testis, meme ve cilt kanseri buna örnektir. $D D X 3 Y$ ve KDM5D genlerinin artan ifadesi baş ve boyun kanserlerinde prognostik öneme sahiptir. ${ }^{[39]}$

\section{SONUÇ}

Son zamanlarda yapılan bazı epidemiyolojik çalışmalar, infertil erkeklerde kansere yatkınlığın olduğunu öngörmektedir. Ancak, erkek infertilitesi ve kanser arasındaki ilişkinin değerlendirildiği çalışmalar ve araştırmalar yetersizdir. Erkek infertilitesi ve kanser arasındaki ilişkinin tam olarak ortaya konulabilmesi için prospektif ve belirli zaman dilimlerine göre düzenlenen, yaşam tarzı faktörlerini de değerlendiren genetik, epigenetik ve yaşam tarzı faktörlerinin dahil edildiği çalışmalara gereksinim duyulmaktadır.

\section{Hakem Değerlendirmesi}

Dış bağımsız

\section{Çıkar Çatışmas}

Yazarlar çıkar ilişkisi olmadığını beyan etmişlerdir.

\section{Finansal Destek}

Herhangi bir mali destek alınmamıştır.

\section{Peer-review}

Externally peer-reviewed.

\section{Conflict of Interest}

No conflict of interest was declared by the authors.

\section{Financial Disclosure}

No financial disclosure was received.

\section{KAYNAKLAR}

1. Gunes S, Esteves SC. Role of genetics and epigenetics in male infertility. Andrologia 2020;53:e13586. [CrossRef]

2. Gunes S, Arslan MA, Hekim GNT, Asci R. The role of epigenetics in idiopathic male infertility. J Assist Reprod Genet 2016;33:55369. [CrossRef]

3. Beyaz CC, Gunes S, Onem K, Kulac T, Asci R. Partial Deletions of Y-Chromosome in Infertile Men with Non-obstructive Azoospermia and Oligoasthenoteratozoospermia in a Turkish Population. In Vivo 2017;31:365-71. [CrossRef]

4. Vander Borght M, Wyns C. Fertility and infertility: Definition and epidemiology. Clin Biochem 2018;62:2-10. [CrossRef]

5. Latif T, Jensen TK, Mehlsen J, Holmboe SA, Brinth L, Pors K, et al. Semen Quality as a Predictor of Subsequent Morbidity: A Danish Cohort Study of 4, 712 Men With Long-Term Follow-up. Am J Epidemiol 2017;186:910-7. [CrossRef]

6. Del Giudice F, Kasman AM, Berardinis ED, Busetto GM, Belladelli F, Eisenberg ML. Association between male infertility and male-specific malignancies: systematic review and metaanalysis of population-based retrospective cohort studies. Fertil Steril 2020;114:984-96. [CrossRef]
7. Raman JD, Nobert CF, Goldstein M. Increased incidence of testicular cancer in men presenting with infertility and abnormal semen analysis. J Urol 2005;174:1819-22; discussion 1822 . [CrossRef]

8. Anderson RE, Hanson HA, Patel DP, Johnstone E, Aston KI, Carrell DT, et al. Cancer risk in first-and second-degree relatives of men with poor semen quality. Fertil Steril 2016;106:731-8. [CrossRef]

9. Walsh TJ, Schembri M, Turek PJ, Chan JM, Carroll PR, Smith JF, et al. Increased risk of high-grade prostate cancer among infertile men. Cancer 2010;116:2140-7. [CrossRef]

10. Hanson HA, Anderson RE, Aston KI, Carrell DT, Smith KR, Hotaling JM. Subfertility increases risk of testicular cancer: evidence from population-based semen samples. Fertil Steril 2016;105:322-8.e1. [CrossRef]

11. Hanahan D, Weinberg RA. Hallmarks of cancer: the next generation. Cell 2011;144:646-74. [CrossRef]

12. Vogelstein B, Papadopoulos N, Velculescu VE, Zhou S, Diaz LA, Kinzler KW. Cancer genome landscapes. Science 2013;339:154658. [CrossRef]

13. Nagirnaja L, Aston KI, Conrad DF. Genetic intersection of male infertility and cancer. Fertil Steril 2018;109:20-6. [CrossRef]

14. Gunes $S$, Kulac T. The role of epigenetics in spermatogenesis. Turk J Urol 2013;39:181-7. [CrossRef]

15. Gunes S, Al-Sadaan M, Agarwal A. Spermatogenesis, DNA damage and DNA repair mechanisms in male infertility. Reprod Biomed Online 2015;31:309-19. [CrossRef]

16. Gunes S, Hekim GNT, Arslan MA, Asci R. Effects of aging on the male reproductive system. J Assist Reprod Genet 2016;33:441-54. [CrossRef]

17. Preston BD, Albertson TM, Herr AJ. DNA replication fidelity and cancer. Semin Cancer Biol 2010;20:281-93. [CrossRef]

18. Jungwirth A, Giwercman A, Tournaye H, Diemer T, Kopa Z, Dohle G, Krausz C. European Association of Urology guidelines on Male Infertility: the 2012 update. Eur Urol 2012;62:324-32. [CrossRef]

19. Hanson B, Johnstone E, Dorais J, Silver B, Peterson CM, Hotaling J. Female infertility, infertility-associated diagnoses, and comorbidities: a review. J Assist Reprod Genet 2017;34:167-77. [CrossRef]

20. Nudell D, Castillo M, Turek PJ, Pera RR. Increased frequency of mutations in DNA from infertile men with meiotic arrest. Hum Reprod 2000;15:1289-94. [CrossRef]

21. Gronberg H. Prostate cancer epidemiology. Lancet 2003;361:85964. [CrossRef]

22. Gunes S, Bagci H, Sarikaya S, Bilen CY, Kara N. Prostate-specific antigen and 17-hydroxylase polymorphic genotypes in patients with prostate cancer and benign prostatic hyperplasia. DNA Cell Biol 2007;26:873-8. [CrossRef]

23. Jorgensen KT, Pedersen BV, Johansen C, Frisch M. Fatherhood status and prostate cancer risk. Cancer 2008;112:919-23. [CrossRef]

24. Barlow C, Hirotsune S, Paylor R, Liyanage M, Eckhaus M, Collins $\mathrm{F}$, et al. Atm-deficient mice: a paradigm of ataxia telangiectasia. Cell 1996;86:159-71. [CrossRef]

25. Xu Y, Baltimore D. Dual roles of ATM in the cellular response to radiation and in cell growth control. Genes Dev 1996;10:240110. [CrossRef]

26. Gordon FKE, Lamb DJ. DNA Repair Genes and Genomic Instability in Severe Male Factor Infertility. In: Carrell DT, editor. The Genetics of Male Infertility. Humana Press; 2006. p.337. [CrossRef] 
27. Zhoucun A, Zhang S, Yang Y, Ma Y, Zhang W, Lin L. The common variant $\mathrm{N} 372 \mathrm{H}$ in BRCA2 gene may be associated with idiopathic male infertility with azoospermia or severe oligozoospermia. Eur J Obstet Gynecol Reprod Biol 2006;124:61-4. [CrossRef]

28. Cheng P, Chen H, Liu SR, Pu XY, A ZC. SNPs in KIT and KITLG genes may be associated with oligospermia in Chinese population. Biomarkers 2013;18:650-4. [CrossRef]

29. Ji G, Long Y, Zhou Y, Huang C, Gu A, Wang X. Common variants in mismatch repair genes associated with increased risk of sperm DNA damage and male infertility. BMC Med 2012;10:49. [CrossRef]

30. Xu J, Jiang L, Yu W, Guo H, Zhang H, Wei D, et al. A novel functional variant in Wilms' Tumor 1 (WT1) is associated with idiopathic non-obstructive azoospermia. Mol Reprod Dev 2017;84:222-8. [CrossRef]

31. Seabra CM, Quental S, Neto AP, Carvalho F, Gonçalves J, Oliveira JP, et al. A novel Alu-mediated microdeletion at $11 \mathrm{p} 13$ removes WT1 in a patient with cryptorchidism and azoospermia. Reprod Biomed Online 2014;29:388-91. [CrossRef]

32. Kido T, Lau YF. Roles of the $Y$ chromosome genes in human cancers. Asian J Androl 2015;17:373-80. [CrossRef]

33. Hotaling JM, Walsh TJ. Male infertility: a risk factor for testicular cancer. Nat Rev Urol 2009;6:550-6. [CrossRef]

34. Maan AA, Eales J, Akbarov A, Rowland J, Xu X, Jobling MA, et al. The Y chromosome: a blueprint for men's health? Eur J Hum Genet 2017;25:1181-8. [CrossRef]
35. Jangravi Z, Alikhani M, Arefnezhad B, Tabar MS, Taleahmad S, Karamzadeh R, et al. A fresh look at the male-specific region of the human Y chromosome. J Proteome Res 2013;12:6-22. [CrossRef]

36. Gunes S, Asci R, Okten G, Atac F, Onat OE, Ogur G, et al. Two males with SRY-positive 46, XX testicular disorder of sex development. Syst Biol Reprod Med 2013;59:42-7. [CrossRef]

37. Krausz C, Degl'Innocenti S. Y chromosome and male infertility: update, 2006. Front Biosci 2005;11:3049-61. [CrossRef]

38. Vergnaud G, Page DC, Simmler MC, Brown L, Rouyer F, Noel B, et al. A deletion map of the human $\mathrm{Y}$ chromosome based on DNA hybridization. Am J Hum Genet 1986;38:109-24. https://www. ncbi.nlm.nih.gov/pmc/articles/PMC1684749/

39. Colaco S, Modi D. Consequences of Y chromosome microdeletions beyond male infertility. J Assist Reprod Genet 2019;36:1329-37. [CrossRef]

40. Komura K, Yoshikawa Y, Shimamura T, Chakraborty G, Gerke TA, Hinohara K, et al. ATR inhibition controls aggressive prostate tumors deficient in Y-linked histone demethylase KDM5D. J Clin Invest 2018;128:2979-95. [CrossRef]

41. Moreno-Mendoza D, Casamonti E, Paoli D, Chianese C, Escamilla AR, Giachini C, et al. Correction: gr/gr deletion predisposes to testicular germ cell tumour independently from altered spermatogenesis: results from the largest European study. Eur J Hum Genet 2020;28:1476. [CrossRef] 